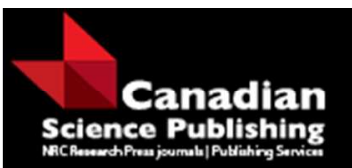

Canadian Journal of Forest Research

Revue canadienne de recherche forestière

\title{
Modeling knot geometry from branch angles in Douglas-fir (Pseudotsuga menziesii)
}

\begin{tabular}{|r|l|}
\hline Journal: & Canadian Journal of Forest Research \\
\hline Manuscript ID & cjfr-2015-0145.R2 \\
\hline Manuscript Type: & Article \\
\hline Date Submitted by the Author: & 09-Oct-2015 \\
\hline Complete List of Authors: & $\begin{array}{l}\text { Osborne, Nathaniel; Oregon State University, College of Forestry } \\
\text { Maguire, Douglas; Oregon State University, College of Forestry }\end{array}$ \\
\hline Keyword: & Knot geometry, Branch angle, Douglas-fir, Wood properties, Pith curvature \\
\hline & \\
\hline
\end{tabular}

\section{SCHOLARONE ${ }^{\text {TM }}$ \\ Manuscripts}


Nathaniel L. Osborne

Douglas A. Maguire

8

College of Forestry 


\section{Abstract}

25 Lumber and veneer recovery from Douglas-fir (Pseudotsuga menziesii) trees depends on the size

26 and distribution of knots. Two approaches have been used to simulate the effect of knots on

27 recovery of these products: (1) prediction of recovery based on mill studies; and (2) simulated

28 milling of virtual trees. A benefit of the latter approach is that different milling configurations

29 may be tested. Knots in virtual logs are usually based on data from X-ray scanning. A novel

30 approach was used in this study to model knot geometry by inferring the development of a

31 branch knot over time from a chronosequence of branch angle and diameter measurements.

32 Branch angle was modeled from a database of 17,953 branch measurements on 412 trees

33 sampled in 16 Douglas-fir plantations. Branch angles from tree tip to crown base were assumed

34 to represent a chronosequence describing the change in branch angle. Knot pith curvature was

35 then derived from this chronosequence of branch angles and modeled as a first degree inverse

36 polynomial, conditioned upon tree size and position within the tree bole. Knot pith curvature was

37 predicted to follow a linear path near the tree tip, and became more curved with increasing age

38 and depth into the crown.

39

40

Key Words

41 Knot geometry; Branch angle; Douglas-fir; Wood properties; Pith curvature

42

43

44

45

46 


\section{Introduction}

48 Knots are one of the most important wood macroscopic features affecting product and value recovery from Douglas-fir (Pseudotsuga menziesii) trees. A knot is formed as a branch grows

50 concurrently with, but generally perpendicular to the tree stem. The wood formed by knots

51 creates discontinuities in longitudinal fibers of the tree bole, reducing wood strength (modulus of

52 rupture), stiffness (modulus of elasticity) and visual appearance (Barbour and Parry 2001). A

53 combination of these wood properties influences product recovery and value (Gartner 2005).

55 Over the last twenty years, numerous product recovery studies have been carried out in the

56 Pacific Northwest (Fahey et al. 1991). These studies have generated product recovery equations

57 that account for the effect of internal knots through surrogate variables like average branch size

58 on the surface of the log. The possibility to link outputs from forest growth models to product

59 recovery equations is well demonstrated (Briggs and Fight 1992; Houllier et al. 1995; Weiskittel

60 et al. 2006). Simulation of tree growth and yield, using a system of forest growth and product

61 recovery equations, assists in the selection of silvicultural treatments to maximize recovery of

62 specific forest products.

63

64 Product recovery equations developed from mill studies depend on mill configuration and on the target products. As a result, these equations provide limited options for exploring alternative products and sawing patterns. A greater versatility for estimating product recovery can be

67 achieved through simulated sawing of virtual logs (Mäkelä et al. 2010). In this approach, 68 products are sawn from three-dimensional virtual logs produced from the outputs of a forest 69 growth and yield model or X-ray scanner, and knot size and location is then evaluated along with 
70 other features to grade the product. Numerous sawing simulators have been developed that vary

71 widely with regard to computational sophistication and required input: SAWSIM (Halco 1970),

72 BOF (Lewis 1985), AutoSaw (Todoroki 1990), RadSawSim (Ištvanić et al. 2010), Grasp

73 (Occeña and Schmoldt 1995), LogCast (Occeña et al. 2000), TopSaw (Yun et al. 2008), Optitek

74 (FPInnovations 2014), WoodCim (Usenius 2000) and Cutlog (Turcan 2005). Analyses have

75 demonstrated that simulated sawing can provide reliable estimates of product recovery (Todoroki

76 et al. 2005).

77

78 A critical step in developing virtual Douglas-fir logs that can be passed from growth models into

79 sawing simulators involves modeling the geometry of knots. The curvature in knot pith between

80 stem pith and stem surface must be modeled accurately to represent the internal knot geometry

81 within the bole and within sawn or peeled wood products (Figure 1). One of the first

82 mathematical models for describing knot shape was developed for Scots pine (Pinus sylvestris)

83 based on assumptions about cross-sectional shape and fixed angles (Samson 1993). Models

84 allowing knot curvature were developed later from data collected on dissected knots in loblolly

85 pine (Pinus taeda) (Trincado and Burkhart 2008), and Norway spruce (Picea abies) (Lemieux et

86 al. 1997). Dissection techniques have increasingly been replaced by X-ray computed

87 tomography (CT). This technique has been used to model knot geometry of Scots pine (Moberg

88 2006), black spruce (Picea mariana), jack pine (Pinus banksiana) (Duchateau et al. 2013),

89 Norway spruce (Andreu and Rinnhofer 2003; Oja 2000; Moberg 2001) and white spruce (Picea

90 glauca) (Tong et al. 2013).

91 
93 Curvature of the knot pith results from a gradual increase in branch angle $(V B A)$ toward a

94 horizontal position (branch angle throughout this analysis refers to angle of origin or angle at

95 point of attachment to the main stem, measured relative to vertical). The angle of a branch

96 formed at the tip of the tree tip defines the initial angle of the knot that eventually results from

97 that branch. Curvature in the knot pith between the bole pith and stem surface (Figure 1)

98 therefore reflects the change in branch angle over time. This time-series of branch angles can be

99 observed in the chronosequence of branch angles from the tree tip to crown base. Inferring a true

100 time-series of branch angles from the chronosequence of branches with increasing age and depth

101 into crown offers a non-destructive sampling approach to construct a database for modeling knot

102 pith curvature. The resulting model assumes that the angle chronosequence over older and deeper

103 branches closely resembles the angle time series as a single branch ages. While quite reasonable

104 from casual observation, the accuracy of this working hypothesis requires testing or validation

105 with data not currently available.

106

107 The ultimate goal of this research was to develop a three-dimensional model for knots within

108 Douglas-fir trees in the Pacific Northwest, so that knot size and location can be projected within

109 virtual logs for sawing simulation. The specific objective of this study was to model the

110 curvature of knots by analyzing a chronosequence of branch angles on standing trees. An

111 assessment of mechanisms controlling knot formation, identification of analytical gaps, and

112 future research needs are also discussed.

114 Methods

115 Field Data 
116 The data used to fit the models for branch angle were first described by Roeh and Maguire

117 (1997) and involved climbing the sample tree and placing a clinometer at the base of whorl

118 branches and reading the angle to the nearest degree from the external scale. The database

119 included 17,953 branch measurements (Table 2) taken from 412 trees (Table 3) across 16 Stand

120 Management Cooperative (SMC) Type I and Type II installations (Maguire et al. 1991). The

121 SMC installations are a network of experimental research plots in managed Douglas-fir forests,

122 covering different levels of initial planting density, site class, and silvicultural treatments that

123 include respacing, thinning, and fertilization.

124

125 Modeling database

126 Construction of a database for modeling knot pith curvature using a chronosequence of branch

127 angles requires two precursor models: 1) a model accounting for the change in branch angle with

128 depth into crown; and 2) a model for estimating diameter inside bark (dib) at any height on the

129 tree bole. Equipped with these models, a suitable database for modeling knot pith curvature can

130 be assembled as a time-series of Cartesian coordinates $(x-y)$ representing the succession of points

131 where the knot pith emerged from the cambial surface at the end of each growing season (Figure

132 2). The $x$-coordinates correspond to the horizontal distance to the bole pith (rib) and the $y$ -

133 coordinates correspond to the height of knot pith at cambial emergence $\left(h_{1}\right)$.

135 A set of segmented polynomial taper models were available for estimation of dib at any height 136 on a Douglas-fir stem (Walters and Hann 1986). Several models for branch angle (VBA) have

137 been presented in the forestry literature (Table 1), including those for Sitka spruce (Picea

138 sitchensis) (Cochrane and Ford 1978), Norway spruce (Colin and Houllier 1992), Douglas-fir 
139 (Roeh and Maguire 1997; Weiskittel et al. 2007a), and Scots pine (Mäkinen and Colin 1998).

140 However, some refinement of the model for Douglas-fir was deemed desirable.

142 Models for Douglas-fir branch angle

143 Two models were developed to predict the insertion angle of live branches from the top to

144 bottom of individual Douglas-fir crowns. Best-subsets regression (regsubsets; leaps package;

145 Lumley 2009) in the R statistical programming language (R Core Team 2015) was used to screen

146 several linearized candidate models and associated explanatory variables. The proposed models

147 are similar to existing equations (Roeh and Maguire 1997; Weiskittel et al. 2007a), with the first

148 taking the following form:

[1] $\quad V B A=\left(\omega_{0}+\omega_{11} C R\right)+\omega_{12}\left[1-e^{\left(\beta_{11} D I N C R+\beta_{12} C L+\beta_{13} \frac{D B H}{H T}\right)}\right]+\varepsilon_{1}$

151 where $V B A$ was branch angle (insertion angle measured from vertical in degrees), $\omega_{0}$ was an 152 empirical minimum value calculated as the upper limit of the $25^{\text {th }}$ percentile of minimum $V B A$ 153 observations for each tree in the modeling database, $\omega_{11}-\omega_{12}$ and $\beta_{11}-\beta_{13}$ were parameters to be 154 estimated from the data, DINC was depth into crown from the tree top (m), $C L$ was live crown 155 length (m), DINCR was relative depth into crown $(D I N C / C L), D B H$ was tree diameter at breast 156 height $(\mathrm{cm}), H T$ was total tree height $(\mathrm{m}), C R$ was live crown ratio $(\mathrm{CL} / \mathrm{HT})$, and $\varepsilon_{1}$ was the error 157 term with $\varepsilon_{1} \sim \mathrm{N}\left(0, \sigma_{\varepsilon 1}{ }^{2}\right)$. The empirically derived minimum value $\left(\omega_{0}\right)$ prevented the model from 158 adverse effects of extremely low values of VBA that were attributable to damaged or malformed 159 branches. 
161 The second model for predicting branch angle allowed a more gradual increase in branch angle

162 with increasing $D I N C R$ by including an effect of branch diameter $(B D)$ :

163

[2] $\quad V B A=\left(\omega_{0}+\omega_{21} C R\right)+\omega_{22}\left[1-e^{\left(\beta_{21} D I N C R+\beta_{22} C L+\beta_{23} D B H+\beta_{24} B D\right)}\right]+\varepsilon_{2}$

164 where $\omega_{21}-\omega_{22}$ and $\beta_{21}-\beta_{24}$ were parameters to be estimated from the data, $B D$ was the

165 measured branch diameter $(\mathrm{mm}), \varepsilon_{2}$ was the error term with $\varepsilon_{2} \sim \mathrm{N}\left(0, \sigma_{\varepsilon 2}{ }^{2}\right)$, and all other variables 166 were defined above.

167

168 Validation of branch angle models

169 Prior to fitting Equation [1] and Equation [2], a validation dataset was constructed. The 170 validation dataset consisted of 3,281 branch measurements from 14 randomly selected SMC

171 plots. The validation dataset represented about $16 \%$ of the entire dataset available for modeling,

172 and both SMC Type I and II installations were represented. The means of the following statistics

173 were computed to validate the branch angle models:

$174 D=$ deviation $\quad=$ observed $V B A-$ predicted $V B A$

$175 A D=$ absolute deviation $=\mid$ deviation $\mid$

$176 D^{2}=$ squared deviation $=$ deviation $^{2}$

177

178 Construction of a dataset for modeling knot pith curvature

179 No attempt was made in this analysis to account for the azimuth of the branch around the

180 circumference of the stem. Until evidence accumulates to the contrary, branch distribution will

181 be assumed to follow a uniform distribution around the stem, as has been found in intensively

182 managed Pinus taeda plantations (Doruska and Burkhart 1994). Annual $x-y$ coordinates were

183 estimated for an average branch at each whorl of each tree sampled to construct the modeling 
184 dataset. This process required the following three steps: (1) reconstruction of the stem dib profile 185 for each year of past tree growth; (2) prediction of branch angle for each year the branch was 186 alive (Equation 1); and (3) numerical solution of these equations to find the $x-y$ coordinates of 187 the intersection of stem $d i b$ profile and knot pith, corresponding to the point of knot pith 188 emergence from the cambium (Figure 2).

The past dib of each tree was estimated from a segmented polynomial taper equation (Walters and Hann 1986). Estimation of past-annual dib profiles from the taper equation required reconstruction of past-annual $D B H, H T$, and $C L$. The past-annual $D B H$ and $H T$ were estimated using a scaling factor, which was the ratio of the current diameter and height to maximum 194 potential diameter and height, for each year of reconstruction. Curves representing cumulative 195 potential diameter growth were estimated using an annualized Douglas-fir $D B H$ growth equation

196 (Weiskittel et al. 2007b) that depended on only initial $D B H$ and site quality (SI). Potential 197 cumulative height growth curves were similarly estimated from a top-height growth equation 198 (King 1966), and rescaled to individual sample trees using the ratio of current tree height to 199 potential top-height for the respective site quality $(S I)$ and tree age. These adjustments of the cumulative $H T$ and $D B H$ growth curves assumed past $D B H$ and $H T$ growth of any given tree had A static allometric equation was developed to estimate height to crown base $(H C B)$ for any year 204 of backdating based on site quality and estimates of that year's $D B H$ and $H T$. This estimate of 205 HCB was used in the taper equation to estimate past dib profile, but also to identify the year of 206 branch mortality. The $H C B$ model was fit by combining eight different datasets from studies 
207 with consistent definitions of $H C B$ (i.e., consistent with "compacted crown ratio" sensu Monleon 208 et al. (2004)). Three of the datasets were from experimental studies of young plantations at five 209 separate locations in western Oregon and Washington, and included tree height and crown base 210 height measurement from time of planting up to ten years of age (Maguire et al. 2009). Three of 211 the datasets included SMC Type I, II, and III plots with measurements from more than 66

212 locations extending from southern Oregon to northern Vancouver Island, and with ages ranging 213 from 4 - 58 years (Maguire et al. 1991). The final two datasets were from long-term studies at 214 five different locations in Oregon and Washington, and included trees ranging in age from 37 21592 years (Ares et al. 2007; Curtis et al. 1997). After testing several candidate models, the 216 following equation was selected:

[3] $\quad H C B=\frac{H T}{1+\exp \left[\alpha_{0}+\alpha_{1} H T+\alpha_{2}\left(\frac{H T}{D B H}\right)+\alpha_{3} S I\right]}+\varepsilon_{3}$

219 where, $H C B$ was height to crown base $(\mathrm{m}), \alpha_{0}-\alpha_{3}$ were parameters to be estimated from the 220 data, SI was King's (1966) site index (m at 50-year breast height age), $\varepsilon_{3}$ was the error term with $221 \varepsilon_{3} \sim \mathrm{N}\left(0, \sigma_{\varepsilon 3}{ }^{2}\right)$, and all other variables were defined above.

223 For each whorl on each tree, a time-series of branch angles $(V B A)$ was predicted starting at the 224 initial whorl height indicated by predicted cumulative tree height growth. After the crown base 225 receded past a given whorl (implying branch mortality), the branch angles in the subsequent part 226 of the time-series for that branch were fixed at the last angle predicted while the branch was still 227 alive.

229 Models for knot pith curvature 
230 Two models for estimating knot pith curvature were fit using the database of $x-y$ coordinates of

231 annual knot pith locations. These models were formulated based upon two potential applications

232 requiring a slightly different set of predictor variables. The first and presumably dominant

233 application was to estimate knot pith curvature during simulation of individual tree growth. In

234 this application, tree level predictors such as $D B H, H T, C L$ and whorl height (height of knot pith

235 origin, $h_{0}$ ) would be available. Several model forms were tested, including a modified Weibull

236 form (Duchateau et al. 2013) and a non-linear form that was a ratio of polynomials of radial

237 distance (Lemieux et al. 1997). The final model was the following first-degree inverse

238 polynomial, selected on the basis of model residual pattern (homogeneity of variance and lack of

239 bias) and expected biological behavior:

240

[4] $\quad H_{\text {rib }}=\frac{r i b}{\left(\gamma_{10}+\gamma_{11} C L+\gamma_{12}\left(\frac{D B H}{H T}\right)\right)+r i b\left(\gamma_{13}+\gamma_{14} r i b_{0}+\gamma_{15}\left(\frac{h_{0}}{H T}\right)\right)}+\varepsilon_{4}$

241 where $H_{r i b}$ was the height of the knot pith above its estimated point of origin at the bole pith

$242(\mathrm{~cm}), h_{0}$ was the simulated whorl height where knot pith was defined to emerge from the bole

243 pith (m), rib $b_{0}$ was the radius inside bark at height $h_{0}(\mathrm{~cm}), r i b$ was the radius inside bark at $H_{r i b}$

$244(\mathrm{~cm}), \gamma_{10}-\gamma_{15}$ were parameters to be estimated from the data, $\varepsilon_{4}$ was the error term with $\varepsilon_{4} \sim$

$245 \mathrm{~N}\left(0, \sigma_{\varepsilon 4}{ }^{2}\right)$, and all other variables were defined above.

247 The second model was developed for instances where only exterior features of the tree, including

248 the height of branch attachment $\left(h_{1}, B R_{h t}\right)$ are available. The final model for this application was

249 the following first-degree inverse polynomial:

$250[5] \quad H_{r i b}=\frac{r i b}{\left(\gamma_{20}+\gamma_{21} C L+\gamma_{22}\left(\frac{D B H}{H T}\right)\right)+r i b\left(\gamma_{23}+\gamma_{24} r i b_{1}+\gamma_{25}\left(\frac{h_{1}}{H T}\right)\right)}+\varepsilon_{5}$ 
251 where $H_{\text {rib }}$ was the height of the knot pith above its estimated point of origin at the bole pith, $h_{1}$

252 was the height of knot pith at emergence from the cambium, $r i b_{l}$ was the radius inside bark at $h_{l}$,

$253 \gamma_{20}-\gamma_{25}$ were parameters to be estimated from the data, $\varepsilon_{5}$ was the error term with $\varepsilon_{5} \sim \mathrm{N}\left(0, \sigma_{\varepsilon 5}{ }^{2}\right)$,

254 and all other variables were defined above.

255

256 The use of the pith curvature models was demonstrated by constructing some three-dimensional

257 knots of the type that would be contained in a virtual tree or log for sawing simulation. Equation

258 [5] was first applied to a tree typical of the Roeh and Maguire (1997) dataset $(D B H=26 \mathrm{~cm}, H T$

$259=16 \mathrm{~m}, C L=14 \mathrm{~m}$ ) to predict the pith or central axis of several branches at different heights

260 within the live crown. The knot diameter at the point of branch insertion was assumed circular

261 and symmetric around the knot pith and equal to the predicted maximum branch diameter

$262\left(B D_{\max }\right)$ at a specific depth into crown (Weiskittel et al. 2007a). The diameter of the knot was

263 assumed to decrease non-linearly as radial distance ( $\mathrm{rib}$ ) approached zero in a manner described

264 by the following equation:

265

[6] $K D=B D_{\max }\left[1-e^{(-\delta \cdot r i b)} / 1-e^{\left(-\delta \cdot r i b_{\max }\right)}\right]$

266 where $K D$ was the knot diameter at $r i b(\mathrm{~cm}), B D_{\max }$ was the predicted maximum branch diameter

267 at the point of insertion $(\mathrm{cm}), \delta$ was a subjectively estimated shape parameter, and rib was radial

268 distance from the tree bole pith $(\mathrm{cm})$.

269 Results

270 Equations [1] and [2] explained $16.6 \%$ and $21.5 \%$, of the variation $\left(\mathrm{R}^{2}\right)$ in branch angle,

271 respectively (Table 4). The residuals for both equations indicated constant variance across the 
272 range of predicted branch angles and depth into crown (Figure 3). Predictions from Equations

273 [1] and [2] indicated that branch angle increased consistently with depth into crown for branches

274 on individual Douglas-fir trees (Figure 4). The trend in branch angle varied by the combination

275 of $D B H, H T$, and $C L$ among individual trees. Large trees and those in a superior social position

276 tended to have a greater initial branch angle, but converged toward the same maximum branch

277 angle at crown base as smaller trees (Figure 5). Equation [2] produced a behavior very similar to

278 Equation [1], but caused the branch angle to change at a slower rate with increasing DINC.

279 Instabilities in Equation [2] were exposed when the model was extrapolated beyond the scope of 280 the modeling dataset. Validation of Equations [1] and [2] suggested that the models performed

281 quite similarly on the validation dataset, with a mean residual that was only a third of a degree in

282 vertical angle, an absolute deviation of approximately $8^{\circ}$, and a mean squared deviation that was

283 very similar to the original model mean squared error (Table 5). A separate and truly

284 independent database of branch angles, as would be available from CT scanning, would facilitate 285 more rigorous validation (Table 5).

287 The model for HCB was required for backdating tree dimensions because, consistent with wide 288 recognition of a functional link between stem profile and crown length (Larson 1963), the taper 289 equations included live crown length as a predictor (Walters and Hann 1986). The HCB model 290 (Equation [3]) explained $92.9 \%$ of the variation in height to crown base (Table 6), and behaved 291 well by providing consistent declines in HCB as tree dimensions were back-predicted.

293 Models predicting knot pith curvature (Equations [4] and [5]) produced estimates consistent with 294 a very limited number of observations of longitudinal-radial sections through knots (Figures 2 
295 and 6). At the tree tip, the path of the knot pith is predicted to be nearly linear in the positive

296 direction. As depth into crown increases, the knot pith becomes more curved towards a

297 horizontal asymptote. Residuals for Equations [4] and [5] indicated homogeneity of variance

298 and no apparent bias. Because Equation [1] smoothed away much of the variation in angles

299 within and among branches, and was then used in constructing the modeling database, both

300 Equations [4] and [5] explained nearly all of the variation in of the resulting knot pith curvature

301 patterns (Table 7). Predicting $H_{r i b}$ from $h_{0}$ versus $h_{l}$ did not change the goodness of fit or

302 residual behavior of Equation [4] or [5].

303

304 The simulated knots resembled curved cones, except that the rate of increase in knot diameter

305 decreased with increasing distance from the bole pith (Figure 7). Knots near the tip of the tree

306 (Figure 7 D) are oriented more vertically and increase in diameter rapidly throughout their

307 length, whereas knots near the base of the crown (Figure 7 A) become more horizontal and are 308 almost cylindrical in shape due to their slow growth rate deep in the crown.

\section{Discussion}

311 Mechanisms controlling branch angle and knot pith curvature

312 Models for knot pith curvature described in this paper predicted only the average trend for a 313 branch within a given whorl. In reality, curvature of different knots would vary within a whorl, 314 because they would exhibit the same degree of variability observed in branch angles within that 315 whorl. Future analysis should consider how to translate the within whorl variation in branch 316 angles into a corresponding set of stochastic knot pith curves. Sets of knot pith curves could be 317 modeled by assuming a specific pattern of autocorrelation through a chronosequence, for 
318

319

320

321

322

323

324

325

326

327

328

329

330

331

332

333

334

335

336

337

338

339

340

example, by assuming that branches remain in the same percentiles of the angle distributions at each whorl age. Alternatively, repeated measurements of specific branches could generate a time series that could be modeled directly, leading to a variety of knot curves within a given whorl. Regardless of the specific approach taken for developing them, a set of knot curves would allow stochastic simulation of knot shape in virtual logs and reproduction of the natural variability that would be observed in real logs. Knot attributes of products generated from simulated sawing of these logs would in turn be very realistic even though the mechanisms generating the variability may not be explicitly represented.

As more information accumulates, it is also conceivable that some of the mechanisms driving the variation in branch angle and knot curvature could be explicitly represented in the models.

Branch angle variation within a whorl presumably results from responses to light gradients, light availability, and associated production and movement of growth regulators that influence the degree of apical control experienced by each branch (Blake et al. 1980; Wilson 1998, 2000). Manipulative experiments that test apical control seem to evoke different responses in different species. For example, removal of apical buds had relatively little effect on the growth of subordinate lateral branches in Nordmann fir (Abies normanniana) (Rasmussen et al. 2010). In a different type of experiment, the loss of apical dominance induced by second flushing in Douglas-fir was reversed by external auxin application (Cline et al. 2006). To our knowledge, no experiments have been conducted to test the effect of differential bud removals from branches within a whorl; however, it would be reasonable to infer that production and movement of growth regulators among branches would control variation in the tendency toward relative apical dominance and plagiotropy within a whorl. Selective pressure for these mechanisms is likely 
341 imposed because they generate a crown architecture that optimizes light interception (and

342 ultimately reproductive success).

344 Other sets of mechanisms influence average branch angle independently of tree height and 345 diameter, and could therefore also help refine the accuracy and precision of knot curvature 346 models. For example, it has been demonstrated that branch angle is partly controlled by genetics 347 (St. Clair 1994). Most forest growth and yield experiments do not take into account the genotype 348 or family of subject trees, unless the field trials are progeny tests designed specifically for tree 349 breeding purposes (Howe et al. 2006), realized gain trials designed to test different mixes of 350 families (e.g., St. Clair et al. 2004), or clonal tests to identify the best performing genotypes (Li 351 et al. 2015). St. Clair (1994) found that individual tree heritability $\left(\mathrm{h}^{2}\right)$ of Douglas fir branch 352 angle was only 0.06 in one progeny test in the Oregon Coast Range, with angles ranging from $353 \quad 32-78^{\circ}$ among individual trees and from $51-59^{\circ}$ for averages among different families. However, 354 others have found heritability as high as 0.49 (Birot and Christophe 1983) and 0.73 (King et al. 355 1992). St. Clair's (1994) results suggest that within a site much of the variation in branch angle 356 is environmentally controlled by the factors referred to above, (i.e., gradients in light intensity).

357 Branch angle will also have influence on crown width (Roeh and Maguire 1997) and therefore 358 may have implications for heritable aspects of crown architecture that influence productivity 359 (Chmura et al. 2007). Although some genetic gain from branch angle selection may be possible 360 if more horizontal or more vertical branches were deemed desirable from either a growth or 361 wood quality perspective, the low to moderate heritability of branch angle and apparent strong 362 influence of the light environment suggest that tree improvement efforts might be better focused 363 on wood properties that have been shown to be more strongly heritable (Howe et al. 2006). 
365 Additional variation might be explained by measuring promising environmental factors 366 associated with site-to-site variation (Hein et al. 2007), after controlling for genetic effects on

367 branch angle. The implication of these effects on wood properties, through their effects on 368 branch angle and corresponding impact on knot curvature and its variability, have not been 369 previously assessed despite the fact that wood properties are known to vary along environmental 370 gradients in Scots pine (Høibø and Vestøl 2010) and Norway spruce (Moberg 2006)

372 Applications and limitations

373 Predicting knot pith curvature from a predicted or measured time-series of branch angles and 374 reconstructed dib profiles is a non-destructive sampling approach that is applicable to monitoring 375 permanent plots, but becomes logistically more difficult and more expensive as trees become 376 taller. Furthermore, branch angles predicted by Equations [1] and [2] apply only to the average 377 of primary branches formed in annual whorls of Douglas-fir. Insertion angle of interwhorl and 378 epicormic branches can be measured and curvature of resulting knots can be estimated on these 379 types of branches in the same way as on whorl branches. Although these branches have been 380 shown to carry a significant amount of foliage in Douglas-fir and therefore may be important for 381 tree growth (Jensen and Long 1983), they have relatively little influence on the properties of 382 structural lumber. Results from both product recovery studies (Fahey et al. 1991) and lumber 383 testing (Whiteside et al. 1977) have indicated that the expected strength of Douglas-fir lumber is 384 correlated with the largest knots in logs and sawn products. 
386 A key assumption in reconstructing knot pith curves from the chronosequence of branch angles

387 was that the tree growth rate in diameter and height maintained the same proportion of the

388 potential growth curves over time. This assumption would hold best for trees in even-aged stands

389 with no silvicultural intervention. Increasingly complex silvicultural regimes will require that the

390 data represent a true time series collected as repeated measurement of individual branches, or

391 that CT scanning techniques be applied to destructively sampled trees near the end of a rotation.

392 Crown responses to thinning and to fertilization (assuming a growth response) would include

393 abrupt shifts in diameter growth and quite possibly in branch angle as well. An advantage of

394 repeated measurements is that, from a silvicultural viewpoint, more insight into the biological

395 causes of internal knot geometry would be gained by directly observing the external response of

396 branches to silvicultural treatments of known intensity. Repeated measurements of branch angle

397 also provide an attractive alternative to destructive sampling, intensive stem dissection, or CT

398 scanning in species of low value or in other situations where resources are limited for modeling

399 knot shape.

400

401 The approach applied in this analysis also can facilitate distinction of the live or tight knot zone

402 from the dead or loose knot zone. Repeated application of the height to crown base model to

403 determine the year of whorl branch mortality provides direct estimation of the live/dead knot

404 transition.

405

406 The dataset used in this analysis came from relatively young, planted Douglas-fir trees (Table 2).

407 To better understand the change in branch angles on planted Douglas-fir over time, additional

408 data should be collected from larger trees, across additional explanatory variables, and over time 
409

410

411

412

413

414

415

416

417

418

419

420

421

422

423

424

\section{Conclusions}

426 Our procedure for constructing a modeling dataset required only three analysis steps: (1)

427 reconstruction of the stem $d i b$ profile for each year of past tree growth; (2) prediction of branch

428 angle for each year of branch growth (Equation 1); and (3) numerical solution to find the $x-y$

429 coordinates for the intersection of stem $d i b$ profile and the branch or knot pith in that year.

430 Using this approach it was possible to model the arc formed by the knot pith at various heights

431 on a Douglas-fir tree. With an assumption of knot size based on modeled trends in $B D_{\max }$ it was 
432 possible to generate a three-dimensional knot. The next step in developing this approach should

433 be validation of models describing knot geometry, preferably by X-ray tomography of whorl

434 sections taken across a wide range of tree size and growing conditions, covering at least the

435 range used for model development (Tables 2 and 3). The knot mapping software, "Gourmands",

436 described by Tong et al. (2013) and developed at the Institut National de la Recherche

437 Agronomique (INRA), demonstrates the potential of X-ray tomography for validation.

439 Acknowledgements

440 Data used in this analysis were made available by the Stand Management Cooperative at the

441 University of Washington. We gratefully acknowledge Doug Mainwaring, David Hann, and

442 Henry Rodman for many helpful suggestions during modeling and manuscript preparation.

\section{Literature Cited}

Andreu, J.P., Rinnhofer, A. 2003. Modeling knot geometry in Norway spruce from industrial CT Images, in: SCIA 2003, pp. 786-791.

Ares, A., Terry, T., Harrington, C., Devine, W. 2007. Biomass removal, soil compaction, and vegetation control effects on five-year growth of Douglas-fir in coastal Washington. Forest Science. 53(5): 600-611.

Barbour, R.J., Parry, D.L. 2001. Log and lumber grades as indicators of wood quality in 20- to 100-year old Douglas-fir trees from thinned and unthinned stands. USDA Forest Service Pacific Northwest Research Station, Portland, Oregon. Gen. Tech. Rep. PNW-GTR-510. 22 p. 
Birot, Y., Christophe, C. 1983. Genetic structures and expected genetic gains from multitrait selection in wild populations of Douglas-fir and sitka spruce. Silvae Genetica 32(5/6): 141-151.

Blake, T.J., Pharis, R.P., Reid, D.M. 1980. Ethylene, gibberellins, auxin and the apical control of branch angle in a conifer, Cupressus arizonica. Planta 148:64-68.

Briggs, D.G., Fight, R.D. 1992. Assessing the effects of silvicultural practices on product quality and value of coast Douglas-fir trees. Forest Products Journal 42(1): 40-46.

Chmura, D.J., Rahman, M.S., Tjoelker, M.G. 2007. Crown structure and biomass allocation patterns modulate aboveground productivity in young loblolly pine and slash pine. Forest Ecology and Management 243(2): 219-230.

Cline, M., Yoder, M., Desai, D., Harrington, C., Carlson, W. 2006. Hormonal control of second flushing in Douglas-fir shoots. Tree Physiology 26:1369-1375.

Cochrane, L., Ford, E.D. 1978. Growth of a Sitka spruce plantation: analysis and stochastic description of the development of branching structure. Journal of Applied Ecology 15: 227-244.

Colin. F., Houllier, F. 1992. Branchiness of Norway spruce in north-eastern France: predicting the main crown characteristics from usual tree measurements. Annals of Forest Science 49(5): 511-538. 
Curtis, R., Marshall, D., Bell, J. 1997. LOGS: a pioneering example of silvicultural research in coast Douglas-fir. Journal of Forestry (USA) 95(7): 19-25.

Doruska, P.F., Burkhart, H.E. 1994. Modeling the diameter and locational distribution of branches within the crowns of loblolly pine trees in unthinned plantations. Canadian Journal of Forest Research 24: 2362-2376.

Duchateau, E., Longuetaud, F., Mothe, F., Ung, C., Auty, D., Achim, A. 2013. Modelling knot morphology as a function of external tree and branch attributes. Canadian Journal of Forest Research, 43(3): 266-277.

Duchateau, E., Auty, D., Mothe, F., Longuetaud, F., Ung, C.H., Achim, A. 2015. Models of knot and stem development in black spruce trees indicate a shift in allocation priority to branches when growth is limited. PeerJ, 3:e873.

Fahey, T.D., Cahill, J.M., Snellgrove, T.A., Heath, L.S. 1991. Lumber and veneer recovery from intensively managed young-growth Douglas-fir. Res. Pap. PNW-RP-437. Portland, OR: U.S. Department of Agriculture, Forest Service, Pacific Northwest Research Station. 25 p.

FPInnovations. 2014. Optitek 10: user's manual. FPInnovations, Quebec, Canada. 
Gartner, B.L. 2005. Assessing wood characteristics and wood quality in intensively managed plantations. Journal of Forestry 103(2): 75-77.

Halco Inc. 1970. SAWSIM: Sawmill Simulation Program, Carroll-Hatch, Vancouver, Canada.

Hein, S., Mäkinen, H., Yue, C., Kohnle, U. 2007. Modelling branch characteristics of Norway spruce from wide spacings in Germany. Forest Ecology and Management 242(2): 155-164.

Høibø, O., Vestøl, G.I. 2010. Modelling the variation in modulus of elasticity and modulus of rupture of Scots pine round timber. Canadian Journal of Forest Research 40(4): 668-678.

Houllier, F., Leban, J., Colin, F. 1995. Linking growth modelling to timber quality assessment for Norway spruce. Forest Ecology and Management 74(1): 91-102.

Howe, G.T., Jayawickrama, K.M., Cherry, Johnson, G. R., Wheeler, N. C. 2006. Breeding Douglas-fir. Plant Breeding Review 27: 245-353.

Ištvanić, J., Piljak, K., Antonović, A., Lưić, R. B., Jambreković, V., Pervan, S. 2010. The Theory and Mathematical Model Underlying the Radial Sawing Simulator-RadSawSim. Forest Products Journal 60(1): 48-56.

Jensen, E.C., Long, J.N. 1983. Crown structure of a co-dominant Douglas-fir. Canadian Journal of Forest Research 13:264-269. 
King, J.E. 1966. Site index curves for Douglas-fir in the Pacific Northwest. Weyerhaeuser For. Pap. 8. Weyerhaeuser Research Technology Center, Federal Way, WA. 49 p.

King, J.N., Yeh, F.C., Heaman, J.C., Dancik, B.P. 1992. Selection of crown form traits in controlled crosses of coastal Douglas-fir. Silvae Genetica 41: 362-370.

Larson, P.R. 1963. Stem form development of forest trees. Forest Science Monograph 5. 42 p.

Lemieux, H., Samson, M., Usenius, A. 1997. Shape and distribution of knots in a sample of Picea abies logs. Scandinavian Journal of Forest Research 12(1): 50-56.

Lewis, D. 1985. Sawmill simulation and the best opening face system: a user's guide. USDA Forest Service, Forest Products Laboratory FPL-48. Madison, WI. 29 p.

Li, Y., Xue, J., Clinton, P.W., Dungey, H.S. 2015. Genetic parameters and clone by environment interactions for growth and foliar nutrient concentrations in radiata pine on 14 widely diverse New Zealand sites. Tree Genetics and Genomes 10(11): 1-16.

Lumley T. 2009. leaps: Regression Subset Selection. R package version 2.9. 
Maguire, D., Bennett, W.S., Kershaw, J. 1991. Establishment report: Stand Management Cooperative silviculture project field installations. College of Forest Resources, University of Washington, Seattle WA. 42 p.

Maguire, D.A., Mainwaring, D.B., Rose, R., Garber, S.M., Dinger, E.J. 2009. Response of coastal Douglas-fir and competing vegetation to repeated and delayed weed control treatments during early plantation development. Canadian Journal of Forest Research 39: 1208-1219.

Mäkelä, A., Grace, J., Deckmyn, G., Kantola, A., Kint, V. 2010. Simulating wood quality in forest management models. Forest systems 19: 48-68.

Mäkinen, H., Colin, F. 1998. Predicting branch angle and branch diameter of Scots pine from usual tree measurements and stand structural information. Canadian Journal of Forest Research 28(11): 1686-1696.

Moberg, L. 2001. Models of internal knot properties for Picea abies. Forest Ecology and Management 147(2): 123-138.

Moberg, L. 2006. Predicting knot properties of Picea abies and Pinus sylvestris from generic tree descriptors. Scandinavian Journal of Forest Research 21(S7): 49-62. 
Monleon, V.J., Azuma, D., Gedney, D. 2004. Equations for predicting uncompacted crown ratio based on compacted crown ratio and tree attributes. Western Journal of Applied Forestry 19(4): $260-267$

Occeña, L.G., Schmoldt, D. L. 1995. GRASP - A Prototype Interactive GRAphical Sawing Program. MU-IE Technical Report, Pp. 1-17.

Occeña, L.G., Santitrakul E., Schmoldt. D.L. 2000. Hardwood sawyer trainer. Pp. 43-47 in Proc. 28th Annual Hardwood Symposium - West Virginia Now - The Future for the Hardwood Industry, Davis, WV. National Hardwood Lumber Assoc., Memphis, TN.

Oja, J. 2000. Evaluation of knot parameters measured automatically in CT-images of Norway spruce (Picea abies (L.) Karst.). European Journal of Wood and Wood Products, 58(5): 375-379.

R Development Core Team. 2015. R: A language and environment for statistical computing. R Foundation for Statistical Computing, Vienna, Austria.

Rasmussen, H.N., Veierskov, B. Hansen-Møller, J., Nørbæk. 2010. “Lateral control”: Phytohormone relations in the conifer treetop and the short- and long-term effects of bud excision in Abies normanniana. Journal of Plant Growth Regulation 19:268-279.

Roeh, R.L., Maguire, D.A. 1997. Crown profile models based on branch attributes in coastal Douglas-fir. Forest Ecology and Management 96(1): 77-100. 
Samson, M. 1993. Modeling of Knots in Logs. Wood Science and Technology 27(6): 429-437.

St. Clair, J.B. 1994. Genetic variation in tree structure and its relation to size in Douglas-fir. II. Crown form, branch characteristics, and foliage characters. Canadian Journal of Forest Research 24(6): 1236-1247.

St. Clair, J.B., Mandel, N.L., Jayawickrama, K.J.S. 2004. Early realized genetic gains for coastal Douglas-fir in the northern Oregon Cascades. Western Journal of Applied Forestry 19(3): 195201.

Sucre, E.B., Harrison, R.B., Turnblom, E.C., Briggs, D.B. 2008. The use of various soil and site variables for estimating growth response of Douglas-fir to multiple applications of urea and determining potential long-term effects on soil properties. Canadian Journal of Forest Research 38: $1458-1469$.

Todoroki, C.L. 1990. AUTOSAW system for sawing simulation. New Zealand Journal of Forestry Science 20(3): 332-348.

Todoroki, C.L., Monserud, R.A., Parry, D.L. 2005. Predicting internal lumber grade from log surface knots: Actual and simulated results. Forest products journal, 55(6): 38-47. 
Tong, Q., Duchesne, I., Belley, D., Beaudoin, M., Swift, E. 2013. Characterization of knots in plantation white spruce. Wood Fiber Sci. 45: 84-97.

Trincado, G., Burkhart, H. 2008. A model of knot shape and volume in loblolly pine trees. Wood and Fiber Science 40(4): 634-646.

Turcan, P. 2005. CutLog: Optimum sawing solution software, Tekl STUDIO. Detva, Slovakia.

Usenius, A. 2000. WoodCim - Integrated planning and optimizing system for sawmilling industry. VTTs Building Technology. Internal Report. 8 p.

Vestøl, G.I., Colin, F., Loubère, M. 1999. Influence of progeny and initial stand density on the relationship between diameter at breast height and knot diameter of Picea abies. Scandinavian Journal of Forest Research 14(5): 470-480.

Walters, D., Hann, D. 1986. Taper equations for six conifer species in southwest Oregon. Forest Research Lab, Oregon State University, Corvallis, OR. Research Bulletin 56.

Weiskittel, A., Maguire, D. 2006. Intensive management influence on Douglas fir stem form, branch characteristics, and simulated product recovery. New Zealand Journal of Forestry Science 36(2/3): 293-312. 
Weiskittel, A.R., Maguire, D.A., Monserud, R.A. 2007a. Modeling crown structural responses to competing vegetation control, thinning, fertilization, and Swiss needle cast in coastal Douglas-fir of the Pacific Northwest, USA. Forest Ecology and Management 245(1): 96-109.

Weiskittel, A.R., Garber, S.M., Johnson, G.P., Maguire, D.A., Monserud, R. A. $2007 b$. Annualized diameter and height growth equations for Pacific Northwest plantation-grown Douglas-fir, western hemlock, and red alder. Forest Ecology and Management 250(3): 266-278.

Weiskittel, A.R., Maguire, D.A., Monserud, R.A. 2007c. Response of branch growth and mortality to silvicultural treatments in coastal Douglas-fir plantations: Implications for predicting tree growth. Forest Ecology and Management 251(3): 182-194.

Whiteside, I.D., Wilcox, M.D., Tustin, J.R. 1977. New Zealand Douglas-fir timber quality in relation to silviculture. New Zealand Journal of Forestry 22:24-44.

Wilson, B.F. 1998. Branches versus stems in woody plants: control of branch diameter growth and angle. Canadian Journal of Botany 76:1852-1856.

Wilson, B.F. 2000. Apical control of branch growth and angle in woody plants. American Journal of Botany 87:601-607. 
Yun, Z., Chang, S., Lei, Z., Gabrielle, A., and Ashwin, B. 2008. Grid-enabled Sawing

Optimization: from scanning images to cutting solution. Proceedings of the 15th ACM Mardi

Gras Conference, Baton Rouge, LA. Pp. 1-8. 


\section{Tables}

Table 1. Definitions and units of variables used in modeling Douglas-fir branch angle and knot pith curvature.

\begin{tabular}{|c|c|c|}
\hline Variable & Definition & Units \\
\hline$V B A$ & Branch angle from vertical & o \\
\hline$C L$ & Crown length & $\mathrm{m}$ \\
\hline$H T$ & Total tree height & $\mathrm{m}$ \\
\hline$H C B$ & Height to the crown base & $\mathrm{m}$ \\
\hline$D B H$ & Diameter at breast height & $\mathrm{cm}$ \\
\hline$B R_{h t}$ & Branch height at insertion & $\mathrm{m}$ \\
\hline$H T_{\text {rel }}$ & $\begin{array}{l}\text { Branch height at insertion relative to } \mathrm{HT} \\
\text { ( } 1 \text { at tree tip to } 0 \text { at tree base) }\end{array}$ & - \\
\hline$B D$ & Branch diameter at the point of insertion & $\mathrm{mm}$ \\
\hline$S I$ & Site index at a base of 50 -years & $\mathrm{m}$ \\
\hline$D I N C$ & Depth into crown & $\mathrm{m}$ \\
\hline$D I N C R$ & $\begin{array}{l}\text { Relative depth into crown } \\
\text { ( } 1 \text { at HCB to } 0 \text { at HT) }\end{array}$ & - \\
\hline$H_{r i b}$ & $\begin{array}{l}\text { Increase in knot pith height from height } \\
\text { where knot pith intersects tree bole pith }\end{array}$ & $\mathrm{cm}$ \\
\hline$r i b$ & Radial distance from the tree bole pith & $\mathrm{cm}$ \\
\hline$r i b_{1}$ & $\begin{array}{l}\text { Radius inside bark of the tree at height of } \\
\text { knot pith emergence from cambium }\end{array}$ & $\mathrm{cm}$ \\
\hline$r i b_{0}$ & $\begin{array}{l}\text { Radius inside bark of the tree at height of } \\
\text { intersection of knot pith and tree bole pith }\end{array}$ & $\mathrm{cm}$ \\
\hline$h_{1}$ & $\begin{array}{l}\text { Height of knot pith at emergence from the } \\
\text { cambium }\end{array}$ & $\mathrm{m}$ \\
\hline$h_{0}$ & $\begin{array}{l}\text { Height of knot pith at intersection of knot } \\
\text { pith and tree bole pith }\end{array}$ & $\mathrm{m}$ \\
\hline
\end{tabular}


Table 2. Attributes of Douglas-fir plots and installations on which sample trees were measured for branch angle and diameter. Trees were sampled from 38 plots on 10 Stand Management Cooperative Type I installations and 16 plots on 6 Type II installations.

\begin{tabular}{lllll}
\hline Attribute & Mean & Standard Deviation & Minimum & Maximum \\
\hline Type I: & & & & \\
Total basal area $\left(\mathrm{m}^{2} \mathrm{ha}^{-1}\right)$ & 10.4 & 7.6 & 0.8 & 26.1 \\
Relative density (\%) & 18.8 & 12.8 & 2.1 & 45.1 \\
Trees per hectare & 703 & 447 & 188 & 2,085 \\
Breast height age & 9 & 3 & 3 & 14 \\
Elevation (m) & 368 & 224.5 & 167.6 & 822.9 \\
Site index (m) & 36.5 & 3.6 & 27.4 & 42.6 \\
& & & & \\
Type II: & & & & \\
Total basal area $\left(\mathrm{m}^{2} \mathrm{ha}^{-1}\right)$ & 32.2 & 7.1 & 19.9 & 41.5 \\
Relative density $(\%)$ & 44.8 & 9.6 & 29.7 & 62.2 \\
Trees per hectare & 680 & 226 & 420 & 1,384 \\
Breast height age & 21 & 4 & 16 & 27 \\
Elevation (m) & 406.5 & 226.8 & 32 & 431.5 \\
Site index (m) & 36.5 & 3.3 & & \\
\hline
\end{tabular}


Table 3. Attributes of Douglas-fir trees measured for branch angle and diameter. Angles of origin were measured on 15,662 branches from 287 trees on 10 Stand Management Cooperative Type I installations and from 2,291 branches from 125 trees on 6 Type II installations.

\begin{tabular}{|c|c|c|c|c|}
\hline Attribute & Mean & Standard Deviation & Minimum & Maximum \\
\hline \multicolumn{5}{|l|}{ Type I: } \\
\hline $\mathrm{DBH}(\mathrm{cm})$ & 14.5 & 5 & 3.3 & 26.6 \\
\hline HT (m) & 10 & 3.1 & 3.8 & 22.5 \\
\hline $\mathrm{CL}(\mathrm{m})$ & 9 & 3 & 2.7 & 20.9 \\
\hline $\operatorname{VBA}\left(\left(^{\circ}\right)\right.$ & 67.9 & 12.7 & 0 & 160 \\
\hline $\mathrm{BD}(\mathrm{mm})$ & 20.9 & 6.9 & 1 & 75 \\
\hline $\mathrm{HT}_{\mathrm{rel}}$ & 0.3 & 0.1 & 0 & 0.8 \\
\hline \multicolumn{5}{|l|}{ Type II: } \\
\hline $\mathrm{DBH}(\mathrm{cm})$ & 28.3 & 6.7 & 14.8 & 46.2 \\
\hline $\mathrm{HT}(\mathrm{cm})$ & 22.1 & 4.7 & 14.3 & 34.6 \\
\hline CL (m) & 19.4 & 5.1 & 11.3 & 32.9 \\
\hline $\operatorname{VBA}\left(^{\circ}\right)$ & 74.6 & 10.9 & 3 & 138 \\
\hline $\mathrm{BD}(\mathrm{mm})$ & 22.9 & 6.7 & 5 & 64 \\
\hline $\mathrm{HT}_{\mathrm{rel}}$ & 0.2 & 0.09 & 0 & 0.5 \\
\hline
\end{tabular}


Table 4. Parameter estimates and fit statistics for the models describing the vertical trend in branch angle (Equation [1] and Equation [2]). All $p$-values of estimated parameters were less than 0.001 .

\begin{tabular}{|c|c|c|c|}
\hline Parameter & Variable & Estimated value & Standard Error \\
\hline \multicolumn{4}{|l|}{ Equation [1] } \\
\hline$\omega_{0}$ & - & 37 & - \\
\hline$\omega_{11}$ & $C R$ & 10.7130 & 1.5767 \\
\hline$\omega_{12}$ & - & 35.1457 & 1.5161 \\
\hline$\beta_{11}$ & $D I N C R$ & -1.1599 & 0.0719 \\
\hline$\beta_{12}$ & $C L$ & -0.0623 & 0.0057 \\
\hline \multirow[t]{2}{*}{$\beta_{13}$} & $D B H / H T$ & 0.3026 & 0.0363 \\
\hline & & RMSE: 11.43 & $\mathrm{R}^{2}: 17.6 \%$ \\
\hline \multicolumn{4}{|l|}{ Equation [2] } \\
\hline$\omega_{0}$ & - & 37 & - \\
\hline$\omega_{21}$ & $C R$ & 8.3492 & 1.2202 \\
\hline$\omega_{22}$ & - & 38.1013 & 1.0207 \\
\hline$\beta_{21}$ & $D I N C R$ & -1.2481 & 0.0637 \\
\hline$\beta_{22}$ & $C L$ & -0.0265 & 0.0051 \\
\hline$\beta_{23}$ & $D B H$ & -0.0432 & 0.0039 \\
\hline \multirow[t]{2}{*}{$\beta_{24}$} & $B D$ & 0.03755 & 0.0025 \\
\hline & & RMSE: 11.16 & $\mathrm{R}^{2}: 21.5 \%$ \\
\hline
\end{tabular}


Table 5. Mean fit and validation statistics for Equation [1] and Equation [2]. Validation data consisted of 3,281 branch angle measurements from 14 plots and 9 installations in the Roeh and Maguire (1997) dataset.

\begin{tabular}{lcccc}
\hline Equation & Dataset & Mean $\boldsymbol{D}$ & Mean $\left.\boldsymbol{A D} \mathbf{(}^{\mathbf{0}}\right)$ & Mean $\boldsymbol{D}^{\mathbf{2}}$ \\
\hline Equation [1] & Modeling data & -0.03 & 8.59 & 130.61 \\
& Validation data & -0.14 & 8.70 & 143.99 \\
Equation [2] & Modeling data & -0.05 & 8.38 & 124.39 \\
& Validation data & -0.32 & 8.23 & 130.58 \\
\hline
\end{tabular}


Table 6. Parameter estimates for modeling height to crown base using Equation [3]. All $p$-values of estimated parameters were less than 0.001 .

\begin{tabular}{cccc}
\hline Parameter & Variable & Estimated value & Standard Error \\
\hline$\alpha_{0}$ & - & 2.5857 & 0.0138 \\
$\alpha_{1}$ & $H T$ & -0.0847 & 0.0002 \\
$\alpha_{2}$ & $H T / D B H$ & -1.7064 & 0.0085 \\
$\alpha_{3}$ & $S I$ & -0.0133 & 0.0003 \\
& & & $\mathrm{R}^{2}: 92.9 \%$ \\
\hline
\end{tabular}


Table 7. Parameter estimates for Equation [4] and Equation [5] describing knot pith curvature in Douglas-fir trees. All $p$-values of estimated parameters were less than 0.001 .

\begin{tabular}{|c|c|c|c|}
\hline Parameter & Variable & Estimated value & Standard Error \\
\hline \multicolumn{4}{|l|}{ Equation [4] } \\
\hline$\gamma_{10}$ & - & 1.4817 & 0.0072 \\
\hline$\gamma_{11}$ & $C L$ & -0.0043 & 0.0001 \\
\hline$\gamma_{12}$ & $D B H / H T$ & -0.1187 & 0.0035 \\
\hline$\gamma_{13}$ & - & 0.1501 & 0.0008 \\
\hline$\gamma_{14}$ & $r i b_{0}$ & -0.0052 & 0.0000 \\
\hline$\gamma_{15}$ & $h_{0} / H T$ & -0.0867 & 0.0009 \\
\hline & & RMSE: 0.18 & $\mathrm{R}^{2}: 99 \%$ \\
\hline \multicolumn{4}{|l|}{ Equation [5] } \\
\hline$\gamma_{20}$ & - & 1.4803 & 0.0072 \\
\hline$\gamma_{21}$ & $C L$ & -0.0043 & 0.0001 \\
\hline$\gamma_{22}$ & $D B H / H T$ & -0.1182 & 0.0034 \\
\hline$\gamma_{23}$ & - & 0.1506 & 0.0008 \\
\hline$\gamma_{24}$ & $r i b_{1}$ & -0.0052 & 0.0000 \\
\hline$\gamma_{25}$ & $h_{1} / H T$ & -0.0869 & 0.0009 \\
\hline & & RMSE: 0.18 & $\mathrm{R}^{2}: 99 \%$ \\
\hline
\end{tabular}




\section{Figure captions}

Figure 1. Longitudinal-radial section from a Douglas-fir stem exposing the bole and knot pith.

Figure 2. One segment of a tree with annual stem growth layers reconstructed using a dib taper model (Walters and Hann 1986) and a superimposed time-series of branch angles. Points identify the numerical solution for the intersection of (dib/2) and knot pith for each year. A photograph of a similarly sized tree section is provided for reference.

Figure 3. Residuals from Equation [1] for describing the trend in vertical branch angle plotted against predicted branch angle and relative depth into crown.

Figure 4. Observed branch angle (from vertical) over relative depth into crown by quantile of crown length (m) from the Roeh and Maguire (1997) dataset, with trend in branch angle for the median tree of each quantile predicted using Equation [1].

Figure 5. Vertical trend in branch angle predicted by Equation [1] and Equation [2] for three trees covering the size range of the Roeh and Maguire (1997) dataset. 
Figure 6. Knot pith curvature predicted using Equation [5] for branches at several heights $\left(h_{1}\right)$ on a large tree from the Roeh and Maguire (1997) dataset $(D B H=46, H T=31, C L=$ 29). The left panel depicts knot curvature on a relative scale in the stem profile (i.e. height of knot pith divided by maximum height of knot pith; distance from bole pith divided by radius inside bark) and the right pane depicts knot curvature on an absolute scale.

Figure 7. Knot geometry for a typical tree in the Roeh and Maguire (1997) dataset $(D B H=26$, $H T=16, C L=14)$, predicted using Equation [5], Equation [6] and a branch diameter model (Weiskittel et al. 2007a) at several heights along the stem $\left(h_{1}\right)$ : (A) $4 \mathrm{~m},(\mathrm{~B})$ $10 \mathrm{~m},(\mathrm{C}) 12 \mathrm{~m}$ and (D) $14 \mathrm{~m}$. 
Figure 1.

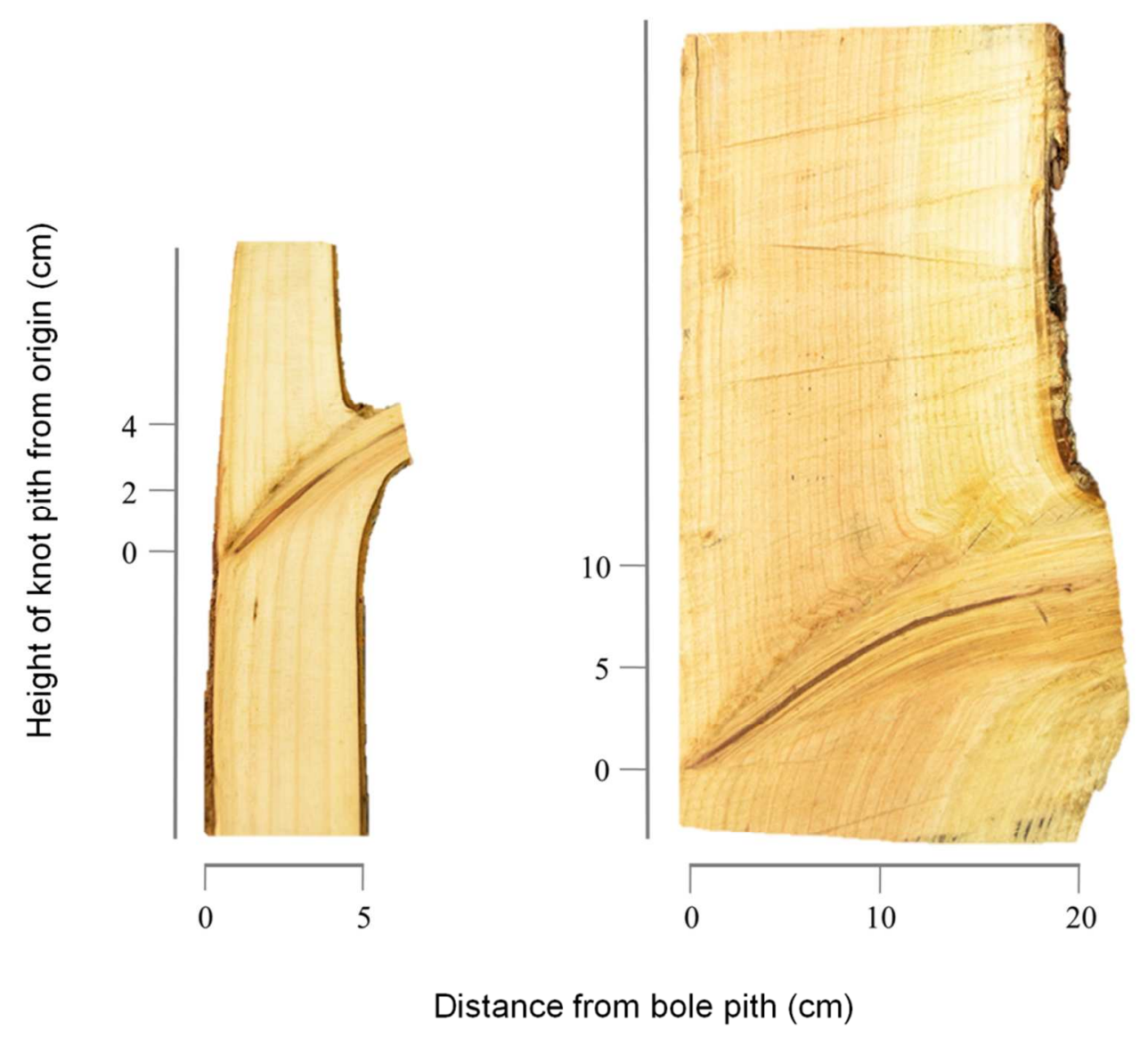

https://mc06.manuscriptcentral.com/cjfr-pubs 
Figure 2.

dib profile $\quad \cdots .$. Branch angle $\quad \circ$ Numerical solution
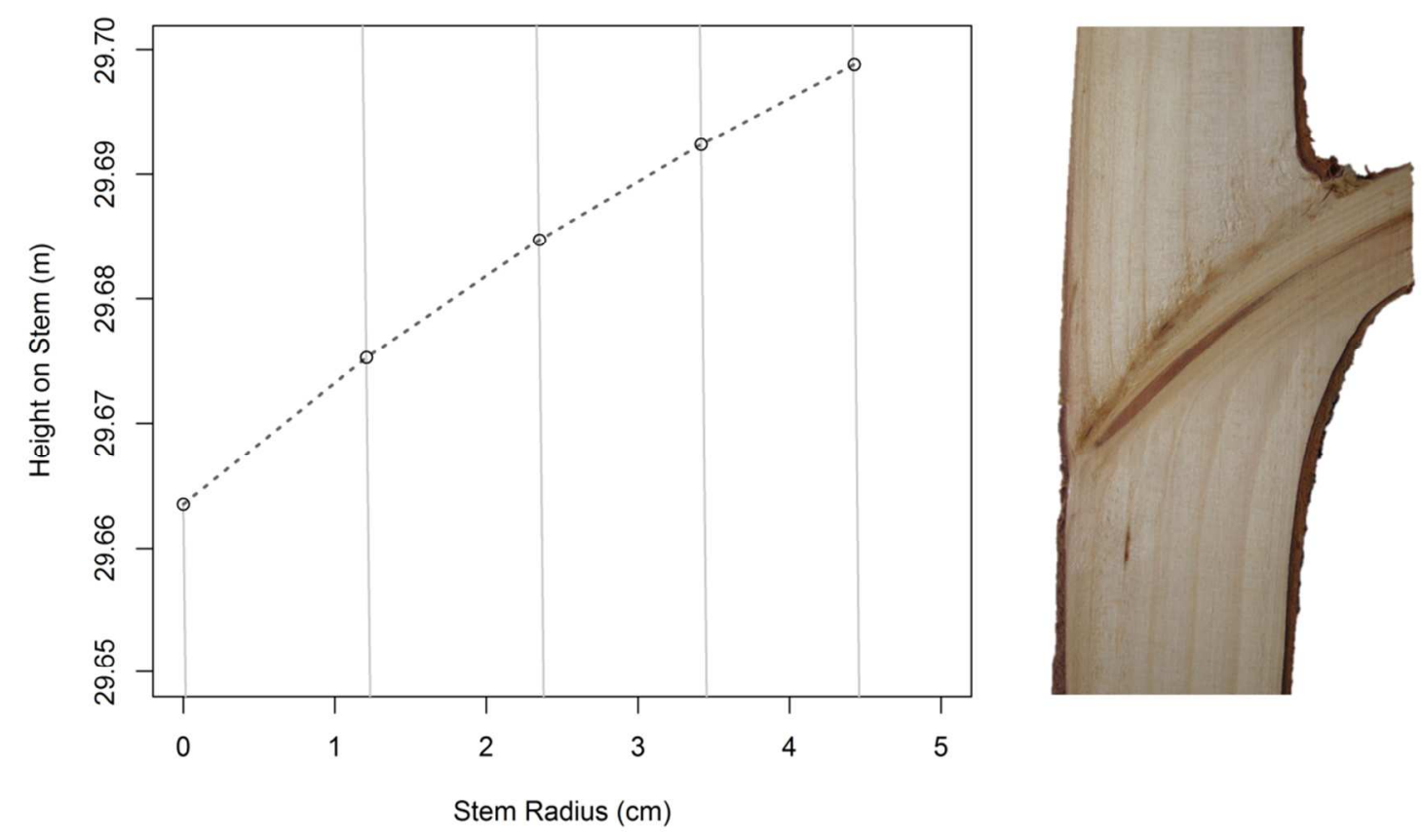
Figure 3.
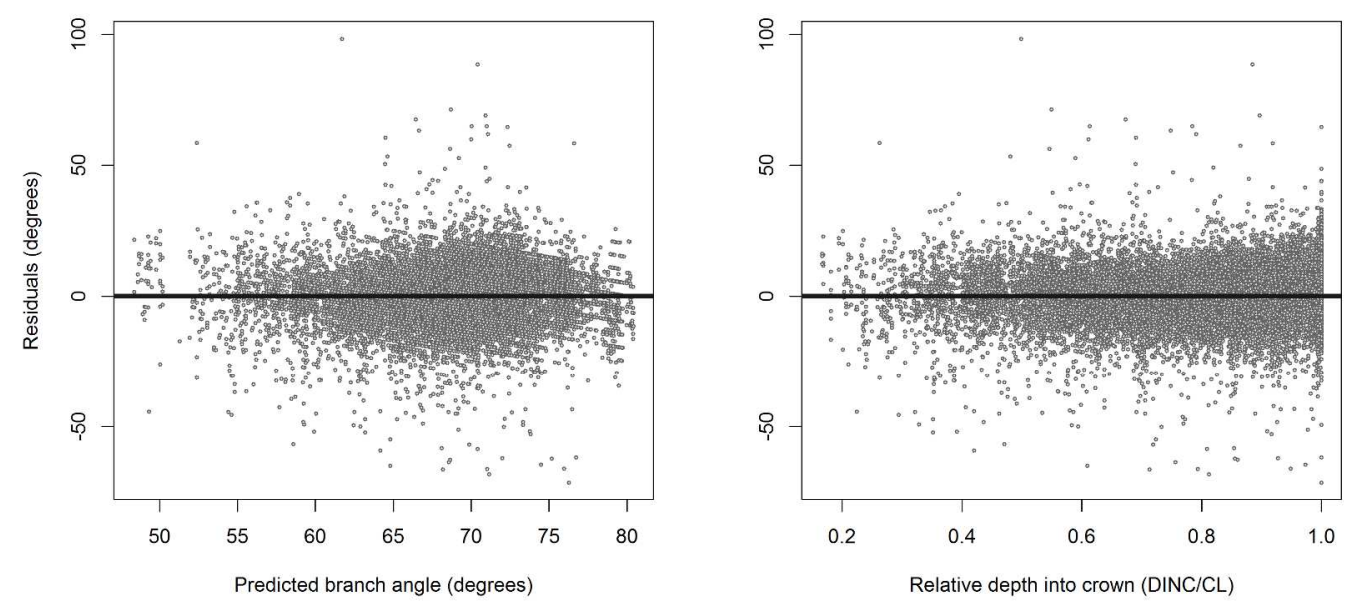
Figure 4.

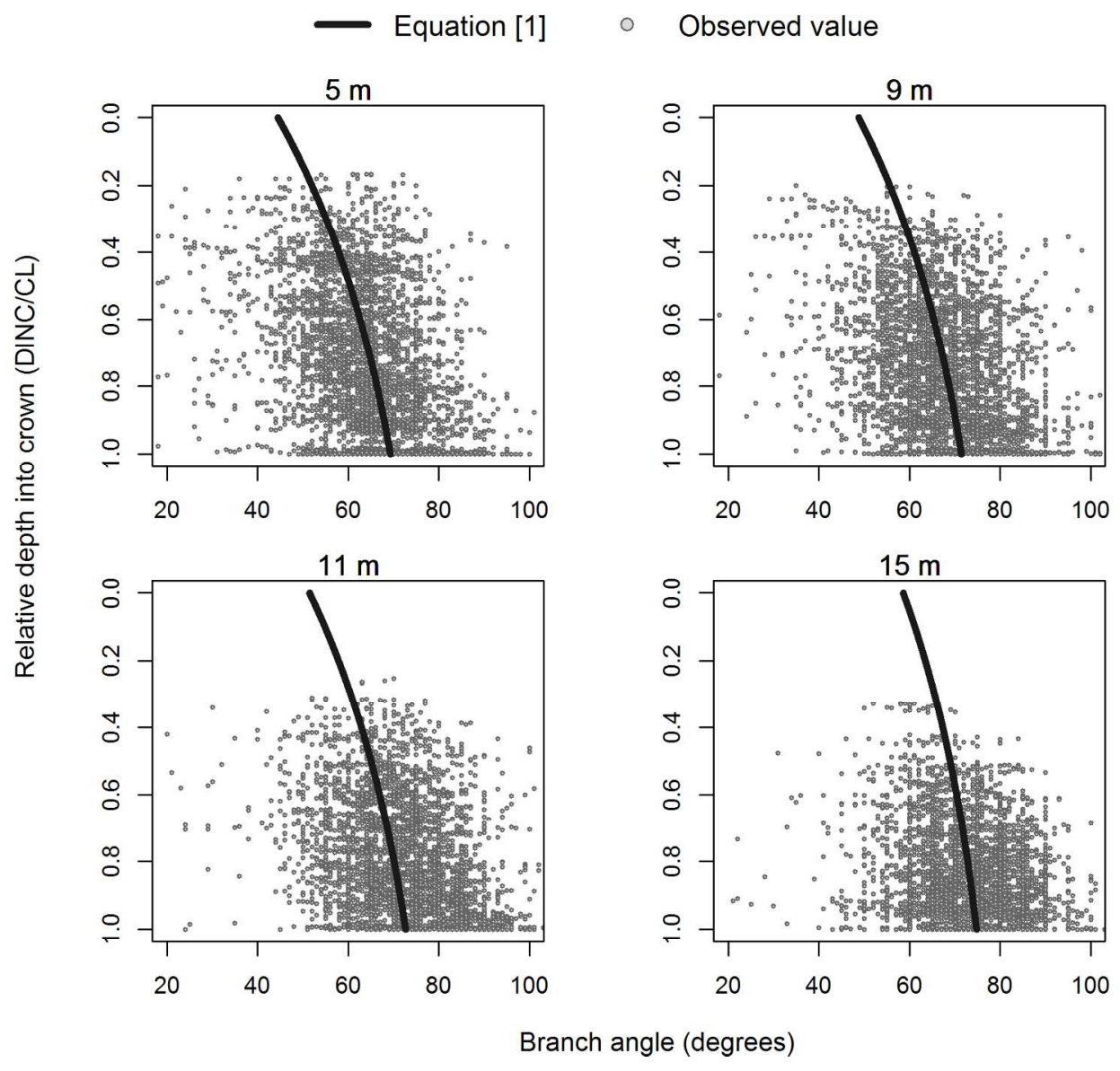


Figure 5.

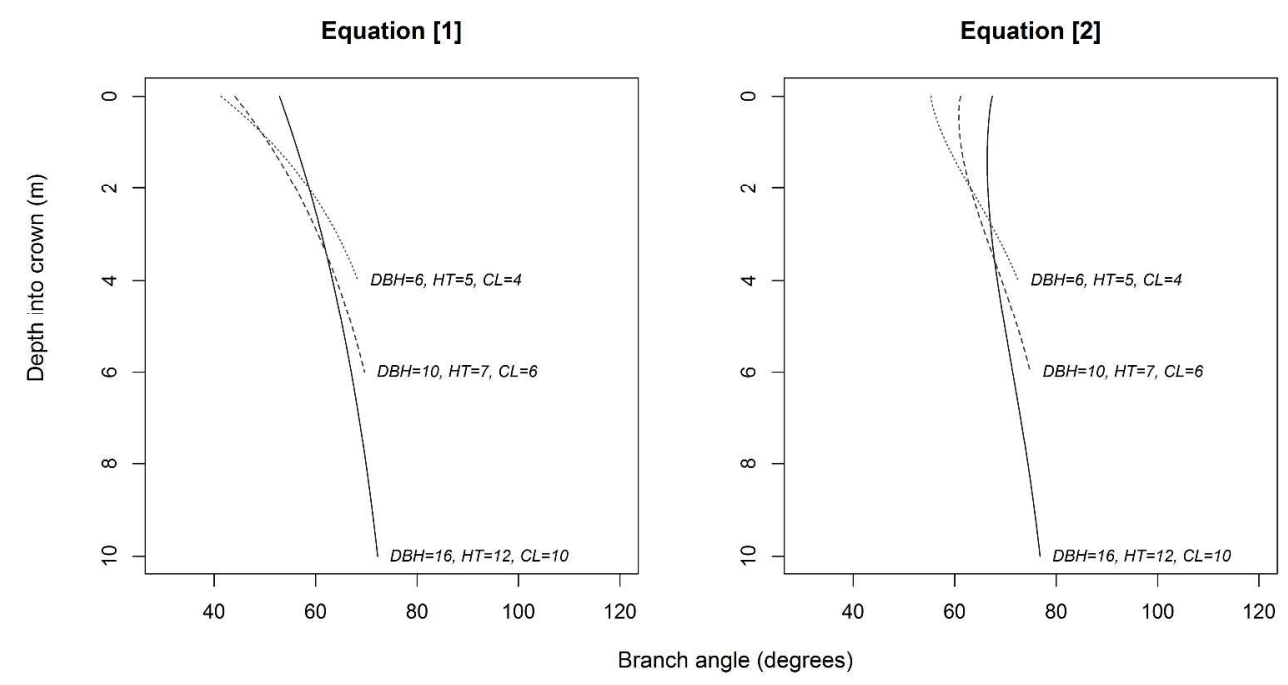

https://mc06.manuscriptcentral.com/cjfr-pubs 
Figure 6.

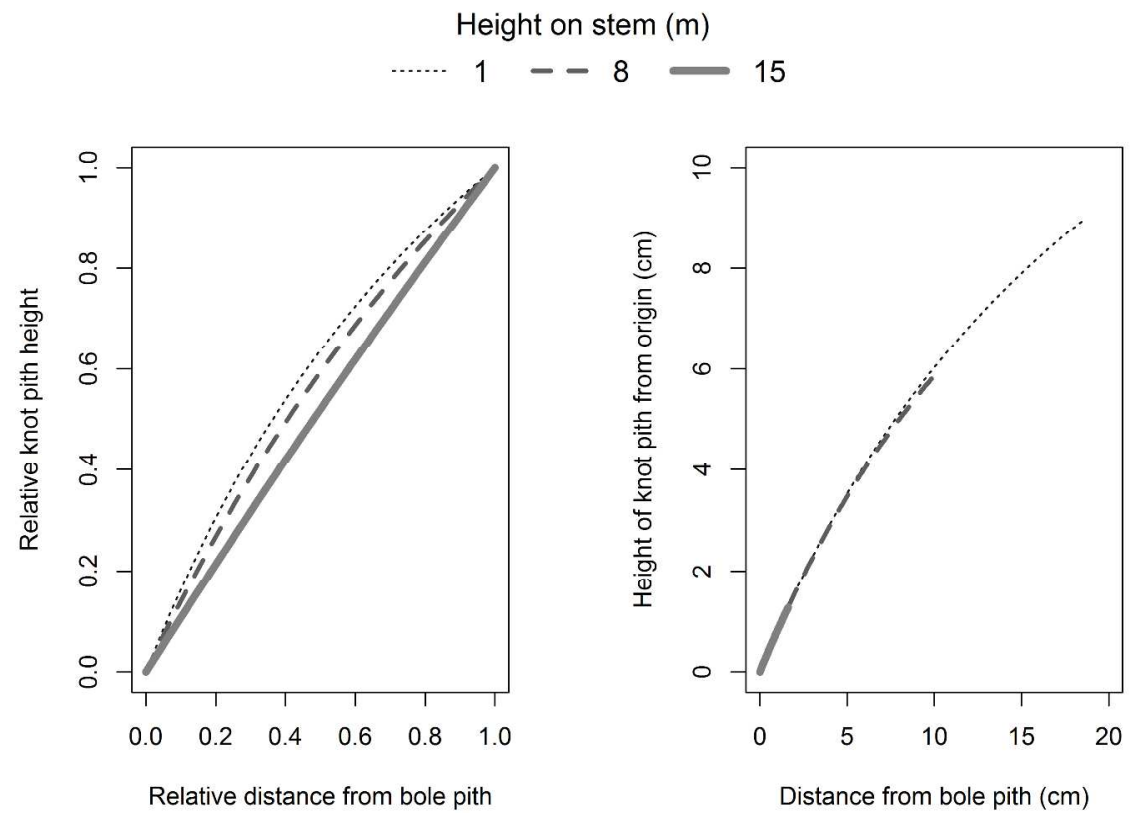


Figure 7.
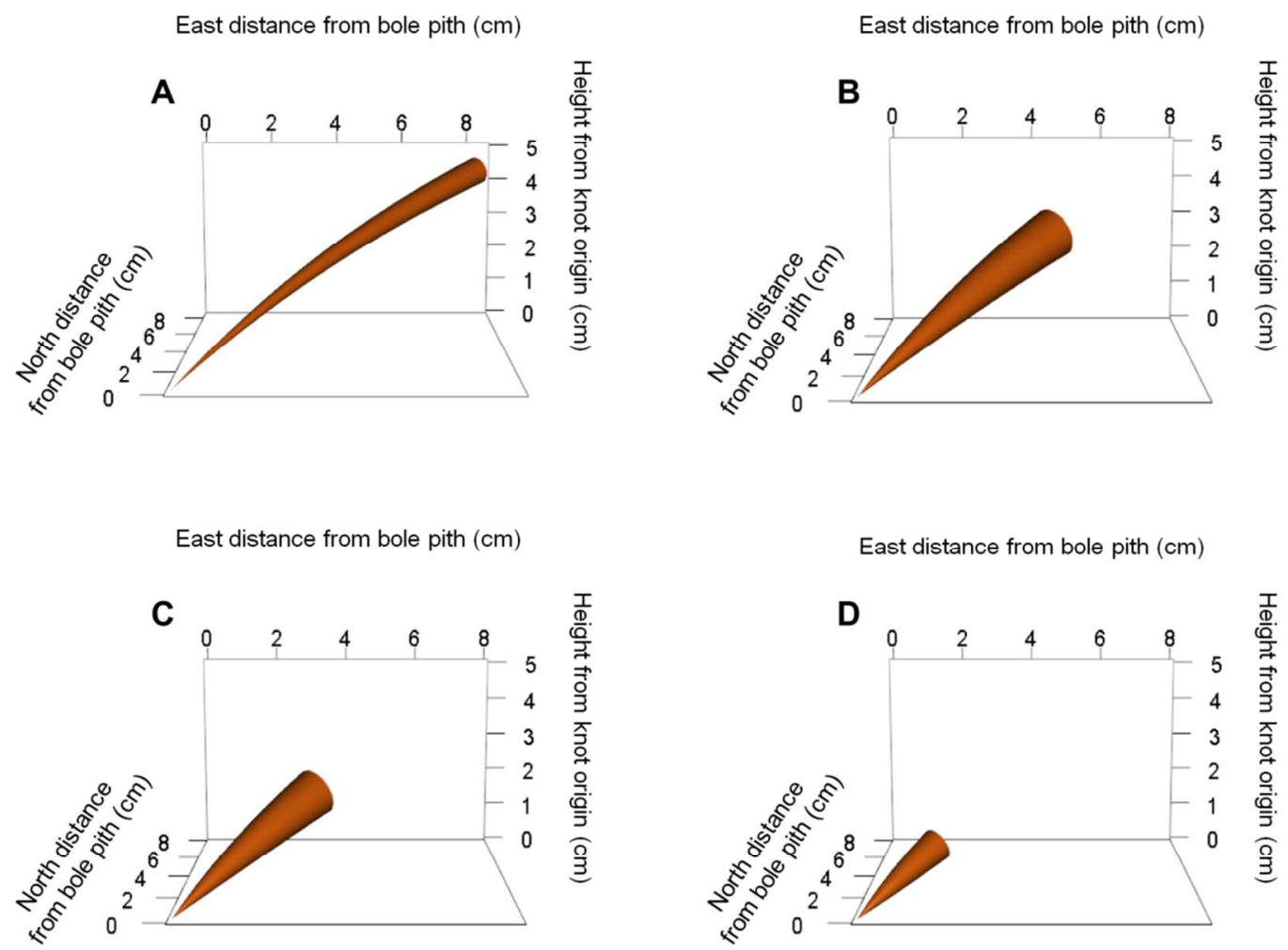